\title{
BMJ Open Does theory of planned behaviour play a role in predicting uptake of colorectal cancer screening? A cross-sectional study in Hong Kong
}

\author{
Junjie Huang (D) , ${ }^{1}$ Jingxuan Wang (D), ${ }^{1}$ Tiffany Wing-Yin Pang (D) , \\ Maggie Ka-Ying Chan, ${ }^{1}$ Sophia Leung, ${ }^{1}$ Xiao Chen (D) , ${ }^{1}$ Colette Leung (D) , 1 \\ Zhi-Jie Zheng (D) , ${ }^{2}$ Martin Chi-Sang Wong (i) ${ }^{1}$
}

To cite: Huang J, Wang J, Pang TW-Y, et al. Does theory of planned behaviour play a role in predicting uptake of colorectal cancer screening? A cross-sectional study in Hong Kong. BMJ Open 2020;10:e037619. doi:10.1136/ bmjopen-2020-037619

- Prepublication history and additional material for this paper are available online. To view these files, please visit the journal online (http://dx.doi. org/10.1136/bmjopen-2020037619).

The abstract of the study was presented at the 6th NCIS Annual Research Meeting (NCAM) 2019, 2-3 August 2019, Singapore.

JH, JW and TW-YP are joint first authors.

Received 10 February 2020

Revised 21 June 2020

Accepted 22 June 2020

Check for updates

(C) Author(s) (or their employer(s)) 2020. Re-use permitted under CC BY-NC. No commercial re-use. See rights and permissions. Published by BMJ.

${ }^{1}$ Jockey Club School of Public Health and Primary Care, Chinese University of Hong Kong, Hong Kong SAR, China ${ }^{2}$ Department of Global Health, School of Public Health, Peking University, Beijing, China

Correspondence to Dr Martin Chi-Sang Wong; wong_martin@cuhk.edu.hk

\section{ABSTRACT}

Objective Colorectal cancer (CRC) ranked second in terms of cancer mortality worldwide. It is associated with a substantial global disease burden. We aimed to examine whether the theory of planned behaviour (TPB) could predict the uptake of faecal immunochemical test to inform novel strategies for enhancing CRC screening participation in population-based programmes.

Design Cross-sectional study.

Settings A Hong Kong-based and territory-wide telephone survey was conducted during the study period from October 2017 to November 2018.

Participants 4800 asymptomatic individuals aged $61-70$ years who can communicate in Cantonese were recruited during the survey period. Those who had a history of CRC, chronic bowel inflammation, two or more first-degree relatives with CRC, and received colonoscopy in the past 10 years or faecal occult blood test in the past 5 years were excluded.

Outcome measures The association between CRC screening uptake and the factors pertinent to TPB was analysed by univariable and multivariable regression models and the mediating effect of intention. We adjusted for age, gender, educational level, marital and working status, as well as household income.

Results Multivariable regression analysis showed that high perceived behavioural control (adjusted OR $(A 0 R)=12.35,95 \% \mathrm{Cl} 8.21$ to $18.60, p<0.001)$, high intention for CRC screening (AOR=7.86, 95\% Cl 6.60 to $9.36, p<0.001$ ) and positive attitude towards CRC screening (accuracy and effectiveness: $A 0 R=1.19$, $95 \% \mathrm{Cl} 1.03$ to $1.38, \mathrm{p}<0.05$; embarrassment and apprehension: $A 0 R=4.27,95 \% \mathrm{Cl} 3.13$ to 5.82, $\mathrm{p}<0.001$ ) were significantly associated with CRC screening uptake. Mediation analysis found that the effect of social norms on screening behaviour was primarily mediated by intention (83.2\%), and this indirect, mediated effect accounted for $21.7 \%$ to $24.1 \%$ of total effects of other constructs in TPB on screening behaviour.

Conclusions The variables pertinent to TPB could successfully predict CRC screening uptake. Promotion of CRC screening based on interventions that increase perceived behavioural control and behavioural intention could potentially enhance screening uptake. Further studies are needed to establish the cause and effect

\section{Strengths and limitations of this study}

- This is the first comprehensive study that examined whether the theory of planned behaviour (TPB) model can predict faecal immunochemical test-based colorectal cancer (CRC) screening uptake in a large asymptomatic population.

- The generalisability of the results to non-participants was good as the study was population-based with a large number of participants recruited by random sampling.

- As we found that the variables pertinent to TPB were significantly associated with the uptake of CRC screening, the findings are useful for formulating effective interventions to enhance screening uptake.

- The cause and effect relationships among the high levels of perceived behavioural control, intention and attitude with CRC screening uptake could not be established as a cross-sectional design was adopted.

- The participants were from a governmentsubsidised CRC screening programme which may differ from other non-subsidised CRC screening programmes in terms of sociodemographic and health consciousness.

- Biases due to recall and social desirability could exist as this was a self-reported telephone survey.

relationship among these variables and screening uptake, as well as to evaluate the cost-effectiveness of such interventions.

\section{BACKGROUND}

Worldwide, colorectal cancer (CRC) is the second leading cause of cancer mortality, accounting for approximately one-tenth of cancer-specific deaths in 2018. ${ }^{1}$ The disease burden has been substantial in Western countries, and in the past decades its global impact has extended to many Asia Pacific countries, such as China, Japan, Korea and Singapore due to its rapidly rising incidence. ${ }^{1}$ In Hong Kong, CRC became the most common cancer 
with over 5000 new cases identified in $2016 .{ }^{2}$ It was the second most common cancer killer in both sexes, where the age-standardised incidence rate was 44.6 for male and 27.6 for female per 100000 standard populations. ${ }^{2}$

International guidelines recommended regular CRC screening for average-risk populations via the detection of cancers at an early curable stage or removal of adenomatous polyps to reduce its related mortality. ${ }^{3-6}$ These guidelines, published by the European Union, ${ }^{3}$ the US Multi-Society Task Force of Colorectal Cancer ${ }^{5}$ and the Asia Pacific Colorectal Working Group, ${ }^{6}$ recommended guaiac-based faecal occult blood test (FOBT), faecal immunochemical test (FIT) and colonoscopy as primary screening tools. ${ }^{4}$ Evidence has indicated that FIT is preferable to guaiac-based FOBT as a screening test because it could be performed without dietary restriction and has higher sensitivity and specificity in detecting CRC. ${ }^{7-9}$

Despite the benefits of CRC screening by FIT, the participation rates remained suboptimal in some countries. ${ }^{1011}$ These include, but are not limited to, Australia (41.3\%), ${ }^{12}$ USA $(48.2 \%),{ }^{13}$ South Korea $(21.0 \%),{ }^{14}$ Taiwan $(21.4 \%){ }^{15}$ and Thailand $(62.9 \%)^{16}$ (online supplementary material 1). The uptake rate of CRC screening is a key performance indicator that exerts a direct impact on programme success. ${ }^{17}$ Determining the impact of individual-level factors associated with screening participation could inform the formulation of strategies to promote CRC screening, as has been suggested in previous studies. ${ }^{18}$

The theory of planned behaviour (TPB) proposes a model on how human behaviour is guided. ${ }^{19}$ It is used to predict the occurrence of a specific action under the circumstance that the action is intentional. Based on the model, human behaviour is guided by three key determinants: overall evaluation of the behaviour (attitudes), estimate of the social pressure (social norms) and beliefs about the ability to perform the behaviour (perceived behavioural control). Previous evaluations found that TPB can predict intentions to attend cancer screening and actual attendance behaviour well, with a medium-sized to a large-sized association for different constructs. ${ }^{20} 21$ However, few studies have examined whether social norms, intention and perceived behavioural control were associated with participation in CRC screening. ${ }^{18}$ Furthermore, there are no studies that have used TPB constructs to explore the reasons for non-participation in FIT-based CRC screening programmes. ${ }^{21} 22$ Therefore, this study aimed to examine whether the constructs under the ТРВ model can predict FIT uptake, so as to inform new strategies that could enhance screening participation in the general population.

\section{METHODS}

\section{Study settings}

A population-based telephone survey among Hong Kong residents aged 61-70 years was performed to evaluate the 3-year Colorectal Cancer Screening Pilot Programme ('pilot programme'). We included Hong
Kong residents who could communicate in Cantonese and lived in their local residence between October 2017 and November 2018. The pilot programme was launched by the Department of Health $(\mathrm{DH})$ to provide screening service from 28 September 2016 to 27 March 2018. Prior to this period, CRC screening service was not available in the public general outpatient clinics, and prospective screening participants should pay out-ofpocket for CRC screening in the private sector. The pilot programme subsidises Hong Kong residents born in the years 1946-1955 to receive CRC services in different phases from the non-public sector, which was defined as private medical service providers. Those with (1) a history of CRC; (2) chronic bowel inflammation; (3) two or more first-degree relatives having CRC; and (3) colonoscopy performed within the past 10 years or receiving FOBT conducted within the past 5 years were excluded. Eligible residents were invited to visit any private clinic with pilot programme signage to join the programme. Physicians in private practice provided medical consultation and FIT package to the participants. Participants were requested to return two faecal samples within 7 days to the designated collection points. Participants with positive test results were arranged for colonoscopy examinations.

\section{Sample size calculation}

Since the pilot programme is the first ever in Hong Kong and the target age group (61-70 years) is different from those in other countries, we assumed $50 \%$ as the proportion in all the outcomes to achieve maximum sample size. A sample size of approximately 1200 screening participants will achieve a precision level of 0.03 , from the following formula: 'precision $=1.96 \times \sqrt{ }[(\mathrm{p}) \times(1 \mathrm{p}) / \mathrm{N}]$ '.

\section{Recruitment of participants}

A total of 4800 respondents were recruited in this study. The 2400 surveyed participants who were enrolled in the programme were randomly selected from a telephone directory and enrolled call list provided by the DH. The other 2400 non-participants were those who are eligible but have not joined or declined to enrol in the pilot programme. The telephone surveys were conducted by the Centre for Behavioural Health of the JC School of Public Health and Primary Care, the Chinese University of Hong Kong. An up-to-date telephone directory was used to select and record random numbers according to page, row and column. Respondents were asked if they had already participated in the study to avoid double counting. Only one respondent was selected for each telephone number to avoid a cluster effect. If the respondent was willing to be involved but was temporarily unavailable, telephone interview for this particular individual was rearranged. Verbal informed consent was obtained through the conversation and the above requirements were met before the interview commenced. 


\section{Study measures}

The primary outcome was screening uptake, which was defined as participation in the CRC screening programme. It was ascertained based on the telephone directory provided by the DH (participants vs nonparticipants). The secondary outcome was screening intention, which was defined as willingness to join the CRC screening programme. It was measured by evaluating how likely a subject is going to participate in the CRC screening programme in the future. Attitudes was defined as a person's overall evaluation of the CRC screening programme. Direct measurement of attitudes involves the use of instrumental items (whether the CRC screening provides benefits; eg, accurate and effective testing for CRC) and experiential items (the perception and feeling of CRC screening participants; eg, embarrassment and apprehension). Social norms refers to beliefs on how significant others would like them to join the CRC screening programme, which consisted of injunctive norms (whether a subject will go for CRC screening if his/ her relatives or friends suggest) and descriptive norms (whether a subject will go for CRC screening if his/her relatives or friends did) ${ }^{23}$ Perceived behavioural control was the extent to which a subject feels able to join the CRC screening programme, which was also measured directly (whether taking the CRC screening tests is easy for the subject) and indirectly (whether the subject will go for CRC screening is entirely up to him or her).

\section{Survey instrument}

A questionnaire designed according to the manual of conducting questionnaires for $\mathrm{TPB}^{24}$ was validated by an expert panel of epidemiologists, gastroenterologists and public health practitioners. The questionnaire collected basic sociodemographic information and quantified the TPB constructs towards CRC screening for each respondent (online supplementary material 2; translated from traditional Chinese). The score for each construct was calculated and compared between CRC screening participants and non-participants. The scores were basically evaluated by a 5 -point semantic differentials/Likert scale with the extreme anchors from 'strongly agree/definitely yes', 'agree/probably yes', 'do not know/not sure', 'disagree/ probably not' and 'strongly disagree/definitely not'.

\section{Statistical analysis}

We used IBM SPSS Statistics V.21.0 to analyse the data. Listwise deletion was used for missing data (completecase analysis) to remove all data for observation with one or more missing values. Descriptive statistics and Pearson's $\chi^{2}$ tests were performed to compare the characteristics between the CRC programme participants and non-participants. Internal consistency reliability analysis was evaluated using items from each subscale to compute the Cronbach's alpha values. A reliability coefficient of 0.6 or higher was considered acceptable in this study. The association between CRC screening uptake (participants coded as ' 1 '; non-participants coded as ' 0 ') and the factors pertinent to TPB was analysed by multivariate regression analysis in three steps. First, the determinants of sociodemographic factors including age, gender, educational level, household income, as well as working and marital status were tested (model 1). Thereafter, factors pertinent to TPB were added to the model (model 2). An interaction term between instrumental and experimental measurements of attitude was further included (model 3). A score of 0-4 was assigned to each variable. Study participants who chose 'strongly agree' and 'definitely yes' had 4 marks; 'agree' and 'probably yes' had 3 marks; 'do not know' and 'not sure' had 2 marks; 'disagree' and 'probably not' had 1 mark; and 'strongly disagree' and 'definitely not' had 0 mark. Mean scores were calculated when multiple questions were used to measure a single construct. Scores $\leq 2$ and $\geq 3$ were considered as 'low' and 'high' levels, respectively. The adjusted ORs (AORs) and $95 \%$ CIs were evaluated in each model. $R^{2}$-based comparison among the three models was tested to learn about the improvement in models' goodness-of-fit among models 1, 2 and 3. The increase in $\mathrm{R}^{2}$ of models 2 and 3 demonstrated the extent to which TPB helps us to understand people's screening behaviour.

To test the mediating effect of intention, we conducted additional analysis where intention was treated as the dependent variable (high level of intention coded as ' 1 '; low level of intention coded as ' 0 '). Attitude, perceived behavioural control, social norms and the factors controlled in model 2 were treated as independent variables in this additional analysis. Based on the results of model 3 and the additional analysis, we constructed a diagram (figure 1) to demonstrate the mediated and unmediated paths. $\mathrm{P}$ values less than 0.05 were considered statistically significant.

\section{Patient and public involvement}

We did not involve patients and the public in the planning or conduct of this specific research project due to time constraints, budgetary constraints and potential bias of reporting in this quantitative study. A qualitative study involving patients and the public was performed in a separate study.

\section{RESULTS}

The total number of telephone calls made to CRC pilot programme participants was 3743 and 69425 for nonparticipants, respectively (online supplementary material 3). Among the participants, there were 67 invalid cases and 1276 unsuccessful cases. Among non-participants, there were more invalid cases (65 543) and unsuccessful cases (1482). A total of 7558 valid calls were made, with a response rate of $63.5 \%$ (65.3\% in screening participants vs $61.8 \%$ in non-participants). The characteristics of the respondents are shown in table 1. Among the 4800 eligible respondents recruited in both groups, their age ranged from 61 to 70 years. The female to male ratio was 1.5:1 (2910 female and 1890 male). The proportion 


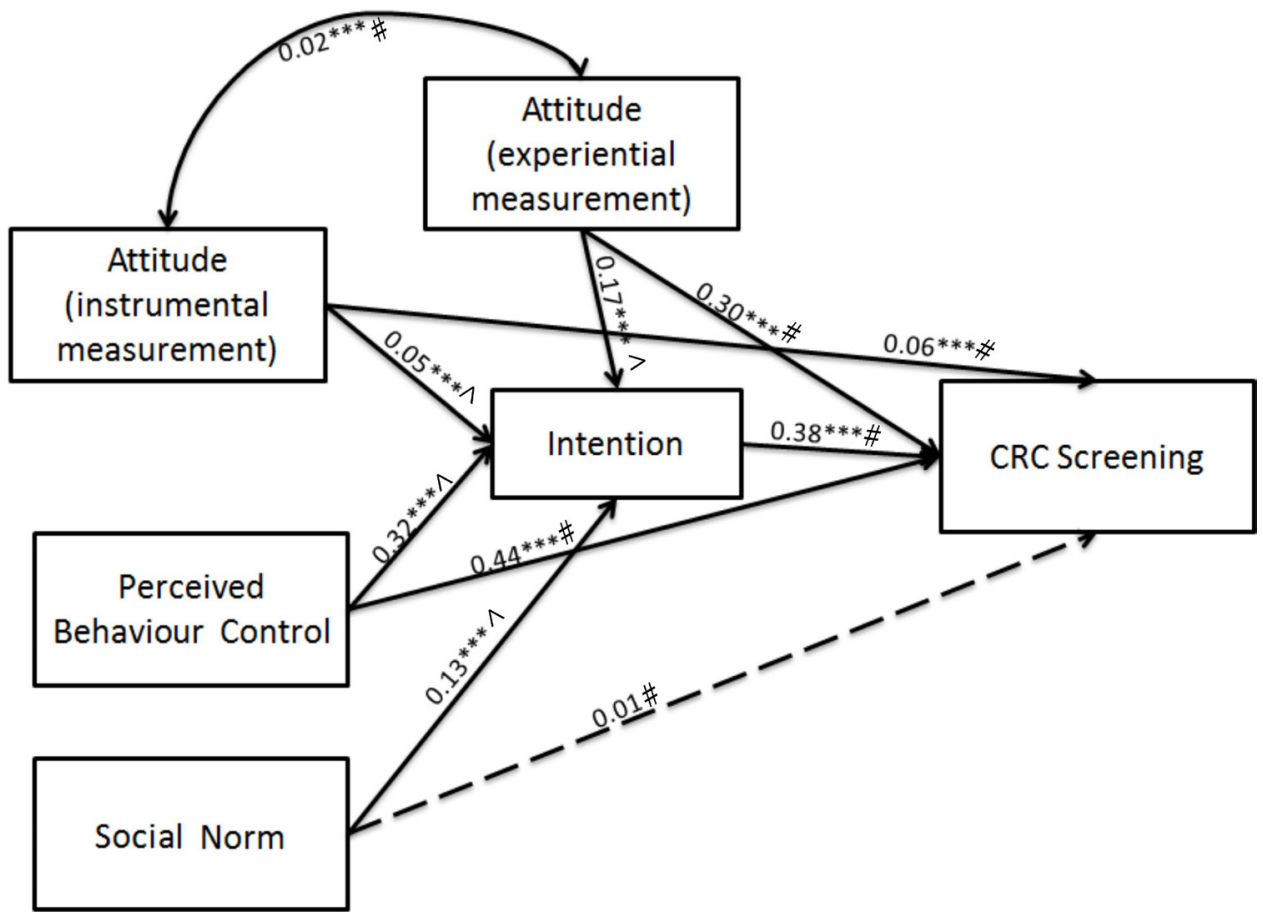

Figure 1 Mediated effects of intention on CRC screening. ${ }^{* *}$ significant at 0.001 level. \#Extracted from model 3 results; coefficients were used to estimate the indirect effects. $\wedge$ Coefficients extracted from the analysis where intention was the independent variable. CRC, colorectal cancer.

of respondents who attained secondary educational level or below was $95 \%$. Over half of the subjects had a monthly household income of $\leq$ HK $\$ 10000$. Between the CRC screening participants and non-participants, the results of all components of TPB were found to be significantly different. Participants had higher levels of intention $(87.6 \%$ vs $48.6 \%)$, instrumental attitude $(54.1 \%$ vs $40.0 \%$ ), social norms (36.3\% vs $31.9 \%$ ), perceived behavioural control $(98.5 \%$ vs $80.2 \%)$ and experiential attitude $(97.2 \%$ vs $85.8 \%)$ when compared with nonparticipants (all $\mathrm{p}<0.001$ ).

Table 2 shows the results of the internal consistency reliability analysis. The Cronbach's alpha coefficient for the three subscales ranged between 0.61 and 0.84 , indicating that the internal consistency of the model was reliable. Pseudo (residuals) $\mathrm{R}^{2}$ increases from $12.2 \%$ in model 1 (baseline model with only sociodemographic predictors) to $29.6 \%$ in model 2 and $29.7 \%$ in model 3 . The substantial improvement in $\mathrm{R}^{2}$ indicates the additional predictive power provided by TPB in understanding subjects' screening behaviour.

Model 1 examined the association between CRC screening uptake and sociodemographic factors. It was found that female subjects (AOR $=0.64,95 \%$ CI 0.56 to $0.73, \mathrm{p}<0.001$ ) were less likely to participate in CRC screening (table 3). Subjects from higher income families $(\mathrm{HK} \$ 10000-19000$ : AOR $=0.51,95 \%$ CI 0.41 to 0.64 , $\mathrm{p}<0.001$; above HK $\$ 20000$ : AOR $=0.57,95 \%$ CI 0.44 to 0.73 , $\mathrm{p}<0.001)$ were less likely to screen for CRC. Older individuals $(\mathrm{AOR}=1.03,95 \%$ CI 1.01 to $1.05, \mathrm{p}<0.01)$ were more likely to participate in the CRC screening programme (age as a continuous variable). A significant association was also observed between CRC screening, marital status and working status. Model 2 tested the variables pertinent to TPB when demographic factors were controlled in model 1. Positive attitude towards CRC screening (direct/ instrumental measurement: $\mathrm{AOR}=1.30,95 \%$ CI 1.14 to $1.48, \mathrm{p}<0.001$; indirect/experiential measurement: $\mathrm{AOR}=4.87,95 \%$ CI 3.63 to $6.52, \mathrm{p}<0.001)$ and higher level of perceived behavioural control (AOR $=17.11,95 \%$ CI 11.52 to $25.41, \mathrm{p}<0.001$ ) were significantly correlated with screening participation. However, social norms did not have a significant relationship with CRC screening. The conclusions remain unchanged after the intention was included in the regression analysis (model 3). High perceived behavioural control $(\mathrm{AOR}=12.35,95 \% \mathrm{CI}=$ 8.21 to $18.60, \mathrm{p}<0.001$ ), high intention for CRC screening (AOR=7.86, 95\% $\mathrm{CI}=6.60$ to $9.36, \mathrm{p}<0.001)$ and positive attitude towards CRC screening (accuracy and effectiveness: AOR=1.19, 95\% CI= 1.03 to 1.38 , $\mathrm{p}<0.05$; embarrassment and apprehension: $\mathrm{AOR}=4.27,95 \% \mathrm{CI}=3.13$ to 5.82 , $\mathrm{p}<0.001$ ) were significantly associated with CRC screening uptake. On the other hand, sociodemographic variables showed that participants with secondary (AOR $=0.81,95 \%$ CI 0.70 to $0.94, \mathrm{p}<0.01)$ or higher $(\mathrm{AOR}=0.70,95 \% \mathrm{CI}$ 0.50 to $0.98, \mathrm{p}<0.05$ ) education had higher intention for CRC screening than others. In contrast, model 1 demonstrated the significant association between marital status ( $\mathrm{AOR}=0.81,95 \%$ CI 0.69 to $0.94, \mathrm{p}<0.01)$ and intention when compared with models 2 and 3 .

To test paths from attitude, perceived behavioural control and social norms to intention, we conducted an additional logistic regression net of the control variables in model 2. Figure 1 summarised the direct 
Table 1 Characteristics of the respondents $(\mathrm{N}=4800)$

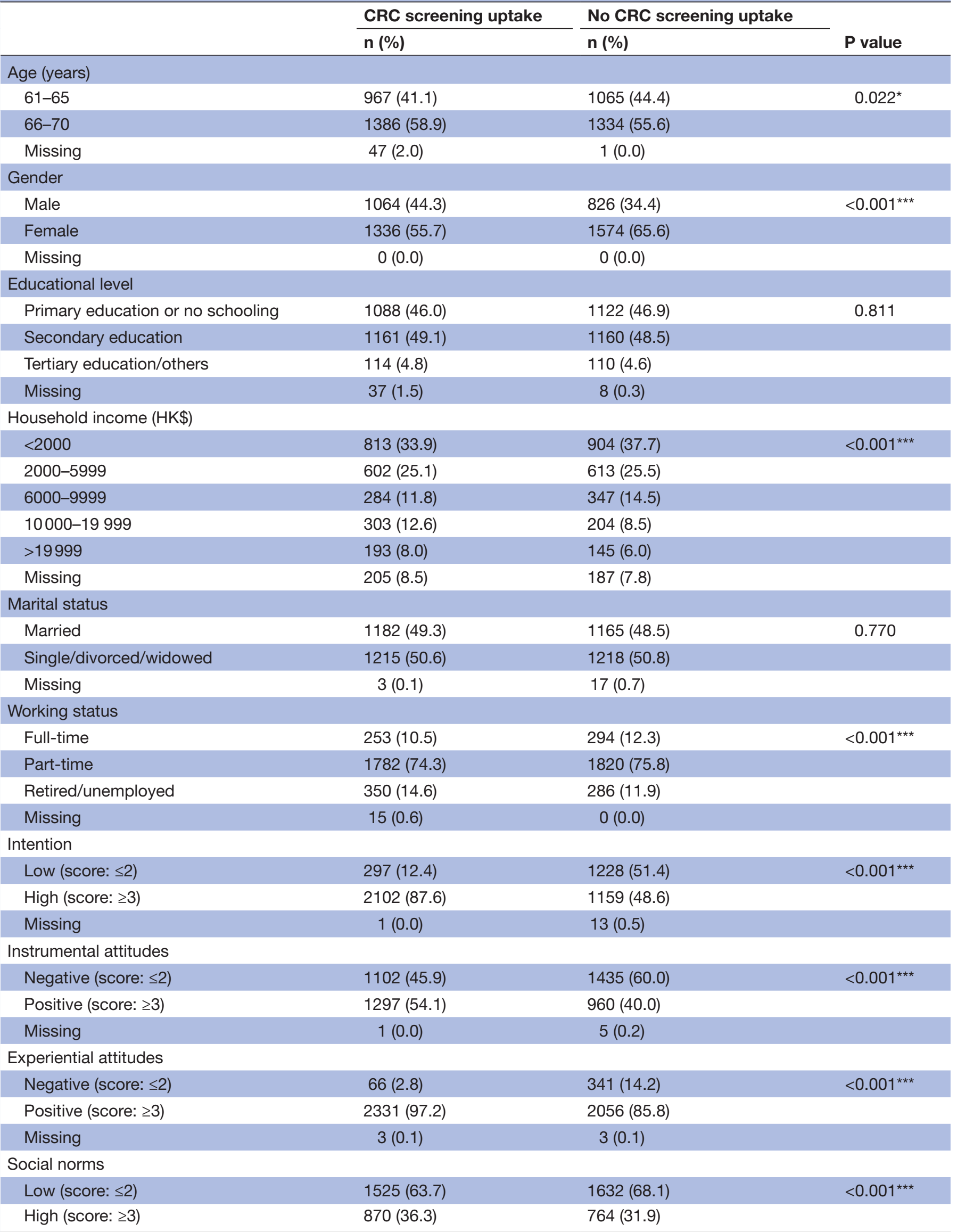


Table 1 Continued

\begin{tabular}{lccc}
\hline & CRC screening uptake & & No CRC screening uptake \\
\cline { 2 - 2 } & $\mathbf{n}(\%)$ & $\mathbf{n}(\%)$ & $13(0.5)$ \\
\hline Missing value & $5(0.2)$ & \\
\hline Perceived behavioural control & $35(1.5)$ & $475(19.8)$ \\
\hline Low (score: $\leq 2)$ & $2361(98.5)$ & $1918(80.2)$ \\
\hline High (score: $\geq 3)$ & $4(0.2)$ & $7(0.3)$ \\
\hline Missing & & \\
\hline
\end{tabular}

Proportions were compared by $\chi^{2}$ tests.

${ }^{*}$ Significant at 0.05 level; ${ }^{* \star}$ significant at 0.01 level; ${ }^{\star \star *}$ significant at 0.001 level.

$\mathrm{CRC}$, colorectal cancer.

and indirect paths from TPB pertinent variables to CRC screening behaviour by combining the results of model 3 and the additional analysis. Intention performed as the mediator from social norms, attitude and perceived behavioural control to CRC screening. Specifically, $24.1 \% \quad((0.05 \times 0.38) /(0.05 \times 0.38+0.06))$ of instrumental attitude's total effect, $17.7 \%((0.17 \times 0.38) /$ $(0.17 \times 0.38+0.30))$ of experiential attitude's total effect, and $21.7 \%((0.32 \times 0.38) /(0.32 \times 0.38+0.44))$ of the total effect of perceived behavioural control were explained by indirect paths through intention for CRC screening $(\mathrm{p}<0.001)$. The influence of social norms is primarily $(83.2 \%, \quad(0.13 \times 0.38) /(0.13 \times 0.38+0.01))$ mediated by intention: direct association between social norms and CRC screening is not significant after controlling for intention for screening $(\mathrm{p}>0.05)$.

\section{DISCUSSION}

\section{Summary}

This was a population-based, representative telephone survey among 4800 participants that examined whether components of the TPB model could predict CRC screening uptake. Overall, the internal consistency of the investigation was good. Female subjects, younger individuals or those with higher income level were less likely to join the government CRC screening programme. Our findings showed that those with a higher level of perceived behavioural control, intention or positive attitude towards CRC screening were associated with higher rates of CRC screening uptake. Among these factors, perceived behavioural control was the strongest predictor, whereas social norms did not play a significant role in CRC screening participation. Behavioural intention could be the mediator for how perceived behavioural control and positive attitude might affect CRC screening uptake.

\section{Comparison with existing literature}

TPB was previously used to foresee CRC screening uptake in Western countries, yet the results varied in different populations, depending on screening modality, location of recruitment, cost and types of invitation to screening. ${ }^{20}$ Devellis $e a^{22}$ reported the first study in 96 high-risk and 144 average-risk subjects in the USA. They found a relatively strong association between perceived behavioural control and CRC screening behaviour, which was consistent with our findings. Another study was conducted in 2426 German male individuals who had different CRC screening behaviours in the past. They concluded that the subjective norm of non-participants remained the highest when compared with other TPB factors, whereas for irregular attenders intention was the strongest predictor of screening uptake. ${ }^{21}$ It is speculated that differences in cultural and demographic factors and the data collection methods of the target populations might have contributed

Table 2 Results of internal consistency reliability analysis

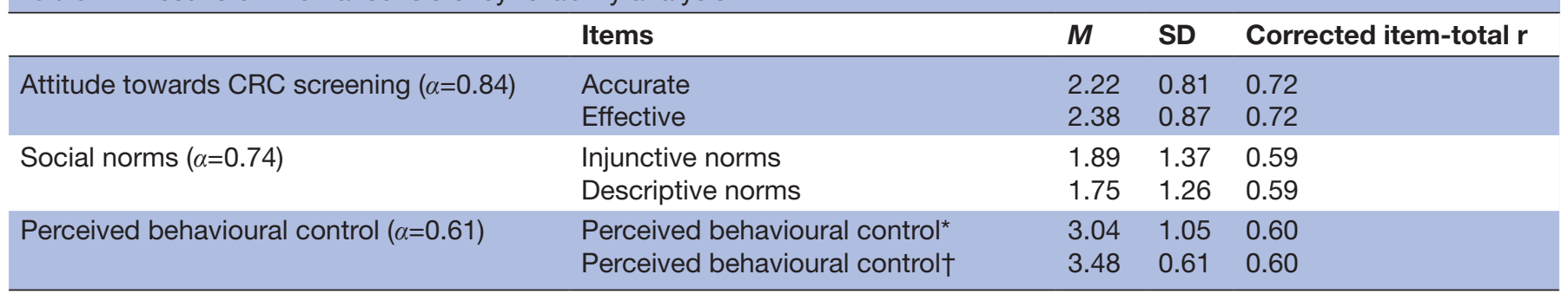

$\alpha$, Cronbach's alpha values.

*Direct measurement.

†Indirect measurement.

CRC, colorectal cancer. 
Table 3 Logistic regression for predicting the uptake of CRC screening

\begin{tabular}{|c|c|c|c|c|c|c|}
\hline & \multicolumn{2}{|c|}{ Model 1} & \multicolumn{2}{|c|}{ Model 2} & \multicolumn{2}{|c|}{ Model 3} \\
\hline & $\begin{array}{l}\text { Adjusted OR } \\
(95 \% \mathrm{Cl})\end{array}$ & $P$ value & Adjusted OR $(95 \% \mathrm{Cl})$ & $P$ value & Adjusted OR (95\% Cl) & $P$ value \\
\hline Age $†$ & 1.03 (1.01 to 1.05$)$ & $<0.01^{\star *}$ & 1.04 (1.02 to 1.06$)$ & $<0.001^{\star \star *}$ & 1.08 (1.05 to 1.10$)$ & $<0.001^{\star \star \star}$ \\
\hline \multicolumn{7}{|l|}{ Gender } \\
\hline Male & Reference & & Reference & & Reference & \\
\hline Female & 0.64 (0.56 to 0.73$)$ & $<0.001^{\star \star \star}$ & 0.69 (0.60 to 0.80$)$ & $<0.001^{\star \star \star}$ & 0.71 (0.60 to 0.83$)$ & $<0.001^{\star \star \star}$ \\
\hline Primary/no schooling & Reference & & Reference & & Reference & \\
\hline Secondary & 0.98 (0.87 to 1.12$)$ & 0.816 & $0.84(0.73$ to 0.97$)$ & $<0.05^{\star}$ & 0.81 (0.70 to 0.94$)$ & $<0.01^{\star *}$ \\
\hline Tertiary/others & 0.92 (0.69 to 1.24$)$ & 0.592 & 0.78 (0.58 to 1.08$)$ & 0.134 & 0.70 (0.50 to 0.98$)$ & $<0.05^{\star}$ \\
\hline \multicolumn{7}{|l|}{ Household income (HK\$) } \\
\hline 10000-19999 & 0.51 (0.41 to 0.64$)$ & $<0.001^{\star \star \star}$ & 0.49 (0.39 to 0.62$)$ & $<0.001^{\star \star \star}$ & 0.55 (0.42 to 0.71$)$ & $<0.001^{\star * *}$ \\
\hline$\geq 20000$ & 0.57 (0.44 to 0.73$)$ & $<0.001^{* * *}$ & 0.48 (0.37 to 0.62$)$ & $<0.001^{\star \star \star}$ & 0.48 (0.36 to 0.63$)$ & $<0.001^{\star \star \star}$ \\
\hline \multicolumn{7}{|l|}{ Marital status } \\
\hline Married & Reference & & Reference & & Reference & \\
\hline Single/divorced/widowed & 0.81 (0.69 to 0.94$)$ & $<0.01^{\star *}$ & 0.87 (0.73 to 1.03$)$ & 0.096 & $1.00(0.84$ to 1.21$)$ & 0.962 \\
\hline \multicolumn{7}{|l|}{ Working status } \\
\hline Full-time & Reference & & Reference & & Reference & \\
\hline Part-time & 0.82 (0.67 to 1.00$)$ & 0.051 & 0.82 (0.66 to 1.01$)$ & 0.063 & 0.78 (0.62 to 0.99$)$ & $<0.05^{\star}$ \\
\hline Retired/unemployed & 0.62 (0.46 to 0.83$)$ & $<0.01^{\star *}$ & 0.65 (0.48 to 0.89$)$ & $<0.01^{\star *}$ & 0.54 (0.39 to 0.76$)$ & $<0.001^{* \star *}$ \\
\hline \multicolumn{7}{|l|}{$\begin{array}{l}\text { Attitude towards CRC } \\
\text { screening }\end{array}$} \\
\hline Positive experiential attitude & & & 4.87 (3.63 to 6.52$)$ & $<0.001^{\star \star *}$ & 4.27 (3.13 to 5.82$)$ & $<0.001^{\star \star \star}$ \\
\hline \multicolumn{7}{|l|}{ Social norms } \\
\hline Low (score: $\leq 2$ ) & & & Reference & & Reference & \\
\hline High (score: $\geq 3$ ) & & & $1.14(0.99$ to 1.31$)$ & 0.071 & 0.88 (0.75 to 1.03$)$ & 0.104 \\
\hline \multicolumn{7}{|l|}{ Perceived behavioural control } \\
\hline Low (score: $\leq 2$ ) & & & Reference & & Reference & \\
\hline High (score: $\geq 3$ ) & & & $17.11(11.52$ to 25.41$)$ & $<0.001^{\star \star *}$ & 12.35 (8.21 to 18.60$)$ & $<0.001^{* \star \star}$ \\
\hline \multicolumn{7}{|l|}{ Intention for CRC screening } \\
\hline Low (score: $\leq 2$ ) & & & & & Reference & \\
\hline High (score: $\geq 3$ ) & & & & & 7.86 (6.60 to 9.36$)$ & $<0.001^{\star \star \star}$ \\
\hline
\end{tabular}

Model 1 examined the association between CRC screening uptake and sociodemographic factors.

Model 2 examined the variables pertinent to TPB when demographic factors were controlled.

Model 3 examined the intention for CRC screening when the variables pertinent to TPB and demographic factors were controlled.

${ }^{*}$ Significant at 0.05 level; **significant at 0.01 level; ${ }^{* * *}$ significant at 0.001 level.

†Age was a continuous variable in the regression model.

$\mathrm{CRC}$, colorectal cancer; TPB, theory of planned behaviour.

to inconsistent findings between studies. Nevertheless, the factors of TPB possess merit in predicting screening uptake in Western countries, ${ }^{21} 22$ and our study is the very first to examine the association between TPB variables and screening uptake in a representative Chinese population. Furthermore, previous studies investigated the influence of TPB constructs on participation in CRC screening using guaiac-based FOBT, while the screening 
modality in the current study is FIT. It was reported that the uptake rates of CRC screening programmes using FIT were much higher than those using guaiac-based FOBT, ${ }^{25}$ and FIT is becoming increasingly popular as a screening tool in CRC screening. ${ }^{26}$

A systematic review and meta-analysis evaluated how well the variables pertinent to ТPB have predicted the intentions and actual behaviour of attending screening programmes, including health checks and screening for genetics, breast, cervical, colorectal and prenatal cancers. ${ }^{20}$ This study found that the magnitude of association between attitudes and intention was high, while that of social norms and perceived behavioural control was relatively modest, which is different from the findings of our study. It may be due to differences in the type of screening test studied, the use of different selection criteria for target population, location of recruitment, screening cost and method of invitation to screening among the studies. Another review on individual-level factors in CRC screening found that theory-based predictions for CRC screening were successful. ${ }^{18}$ However, the evidence base for many of these associations, especially for models that included social norms, perceived behavioural control and intention, was limited. Therefore, this study on variables pertinent to TPB represents a novel evaluation in the context of existing literature.

A study previously conducted in Hong Kong evaluated the determinants of CRC screening behaviour by using variables pertinent to the health belief model to predict CRC screening. ${ }^{27}$ It recruited 1004 residents aged 30-65 in year 2006. It was found that CRC screening uptake was positively associated with increased levels of knowledge of CRC symptoms $(\mathrm{AOR}=3.33)$ and risk factors $(\mathrm{AOR}=2.61)$, while it was negatively associated with perceived severity $(\mathrm{AOR}=0.28)$, health and psychological barriers (AOR=0.42), and access barriers to CRC screening (AOR=0.22). However, this study was different from the present survey in some aspects. The target population of our study were older, with age ranging from 61 to 70 years. Also, we included more participants $(\mathrm{N}=4800)$ in the government-subsidised CRC screening pilot programme. Considering the very large scale and substantial social impacts of government-subsidised programmes all over the world, our study contributes to informing strategies on public education and screening promotion.

\section{Implications for strategies in promoting CRC screening}

The results of our study may inform the formulation of promotional strategies that could enhance screening participation among asymptomatic individuals. Targeted interventions based on enhancing perceived behavioural control, behavioural intention and attitudes could be effective in improving CRC screening uptake. Programme authority and organisations would be recommended to disseminate more information on CRC screening designed to generate positive attitudes and reduce psychological barriers, rather than alter their social norms, to enhance the intention for screening. Educational interventions, such as newspaper advertisements, leaflets or face-to-face discussion, could be useful. However, organised programmes may be necessary as it allows a more extensive coverage and ensures equity of access. The success of enhancing screening uptake also needs a systematic reach of the target population by individual invitation letters signed by family physicians. For non-participants, sending additional reminders by mails may be effective. Another possible strategy to enhance CRC screening programmes is to provide informed choices on screening tools or locations of specimen collection for the population, which may increase the level of perceived behavioural control for the population. We have previously conducted a trial in real-life setting and found participants with an option for screening tool had higher adherence rates than those without, indicating that providing screening tool choices for CRC screening is preferred. ${ }^{28}$ Urging people to form implementation intentions is also important to enhance screening uptake. To achieve this, reminders from physicians or volunteers may be effective. Interactive telephone reminders are more effective compared with short message services when calling patients back for screening according to our previous studies. ${ }^{29}{ }^{30}$ Complex interventions incorporating multiple levels and factors of healthcare outside the individual clinicians' control may also represent effective strategies to promote CRC screening. When implementing the above interventions, more attention needs to be paid to female subjects, younger individuals or those with higher income level as they were less likely to participate in government-subsidised CRC screening programmes. However further studies are needed to evaluate and compare the cost-effectiveness of different strategies in enhancing CRC screening programme uptake.

Contributors MCSW and JH participated in the study concept and design. JH and JW planned the data analysis. JW and TWYP participated in data analysis. MKYC, CL, XC and SL collected the data. JH, JW, TWYP and MKYC drafted the manuscript. MCSW and ZJZ offered intellectual input and provided critical revision of the manuscript. All authors have approved the final version of the manuscript for publication.

Funding This work was supported by the Health and Medical Research Fund (grant number 6904168), Food and Health Bureau, the Hong Kong Government.

\section{Competing interests None declared.}

Patient and public involvement Patients and/or the public were not involved in the design, or conduct, or reporting, or dissemination plans of this research.

Patient consent for publication Not required.

Ethics approval This study was approved by the Chinese University of Hong Kong - New Territories East Cluster Clinical Research Ethics Committee (CREC 2016.485).

Provenance and peer review Not commissioned; externally peer reviewed.

Data availability statement Data are available upon reasonable request.

Open access This is an open access article distributed in accordance with the Creative Commons Attribution Non Commercial (CC BY-NC 4.0) license, which permits others to distribute, remix, adapt, build upon this work non-commercially, and license their derivative works on different terms, provided the original work is properly cited, appropriate credit is given, any changes made indicated, and the use is non-commercial. See: http://creativecommons.org/licenses/by-nc/4.0/.

ORCID iDs

Junjie Huang http://orcid.org/0000-0003-2382-4443

Jingxuan Wang http://orcid.org/0000-0002-1570-7266

Tiffany Wing-Yin Pang http://orcid.org/0000-0003-3906-9999

Xiao Chen http://orcid.org/0000-0002-2108-2215 
Colette Leung http://orcid.org/0000-0002-3130-8783

Zhi-Jie Zheng http://orcid.org/0000-0002-0233-5010

Martin Chi-Sang Wong http://orcid.org/0000-0001-7706-9370

\section{REFERENCES}

1 Bray F, Ferlay J, Soerjomataram I, et al. Global cancer statistics 2018: GLOBOCAN estimates of incidence and mortality worldwide for 36 cancers in 185 countries. CA Cancer J Clin 2018;68:394-424.

2 Hong Kong Cancer Registry.. Overview of Hong Kong cancer statistics of 2016, 2018. Available: http://www3.ha.org.hk/cancereg/ pdf/factsheet/2016/colorectum_2016.pdf [Accessed 1 Jan 2019].

3 European Colorectal Cancer Screening Guidelines Working Group, von Karsa L, Patnick J, et al. European guidelines for quality assurance in colorectal cancer screening and diagnosis: overview and introduction to the full supplement publication. Endoscopy 2013:45:51-9.

4 Rex DK, Boland CR, Dominitz JA, et al. Colorectal cancer screening: recommendations for physicians and patients from the U.S. multi-society task force on colorectal cancer. Am J Gastroenterol 2017;112:1016-30.

5 Sung JJY, Ng SC, Chan FKL, et al. An updated Asia Pacific consensus recommendations on colorectal cancer screening. Gut 2015;64:121-32.

6 Tárraga López PJ, Albero JS, Rodríguez-Montes JA. Primary and secondary prevention of colorectal cancer. Clin Med Insights Gastroenterol 2014;7:33-46.

7 Launoy GD, Bertrand HJ, Berchi C, et al. Evaluation of an immunochemical fecal occult blood test with automated reading in screening for colorectal cancer in a general average-risk population. Int J Cancer 2005;115:493-6.

8 Guittet L, Bouvier V, Mariotte N, et al. Comparison of a guaiac based and an immunochemical faecal occult blood test in screening for colorectal cancer in a general average risk population. Gut 2007;56:210-4.

9 Guittet L, Bouvier V, Mariotte N, et al. Comparison of a guaiac and an immunochemical faecal occult blood test for the detection of colonic lesions according to lesion type and location. $\mathrm{Br} J$ Cancer 2009;100:1230-5.

10 Klabunde C, Blom J, Bulliard J-L, et al. Participation rates for organized colorectal cancer screening programmes: an international comparison. J Med Screen 2015;22:119-26.

11 Navarro M, Nicolas A, Ferrandez A, et al. Colorectal cancer population screening programs worldwide in 2016: an update. World J Gastroenterol 2017;23:3632-42.

12 Australian Institute of Health and Welfare. National bowel cancer screening program: monitoring report 2019, 2019. Available: https:// wwwaihwgovau/reports/cancer-screening/national-bowel-cancerscreening-program-monitoring/contents/table-of-contents [Accessed 23 Mar 2020].

13 Jensen CD, Corley DA, Quinn VP, et al. Fecal immunochemical test program performance over 4 rounds of annual screening: a retrospective cohort study. Ann Intern Med 2016;164:456-63.

14 Suh M, Song S, Cho HN, et al. Trends in participation rates for the National cancer screening program in Korea, 2002-2012. Cancer Res Treat 2017;49:798-806.
15 Chiu H-M, Chen SL-S, Yen AM-F, et al. Effectiveness of fecal immunochemical testing in reducing colorectal cancer mortality from the one million Taiwanese screening program. Cancer 2015;121:3221-9.

16 Khuhaprema T, Sangrajrang S, Lalitwongsa S, et al. Organised colorectal cancer screening in Lampang Province, Thailand: preliminary results from a pilot implementation programme. BMJ Open 2014;4:e003671

17 Zorzi M, Senore C, Da Re F, et al. Quality of colonoscopy in an organised colorectal cancer screening programme with immunochemical faecal occult blood test: the EQuIPE study (evaluating quality indicators of the performance of endoscopy). Gut 2015;64:1389-96.

18 Kiviniemi MT, Bennett A, Zaiter M, et al. Individual-level factors in colorectal cancer screening: a review of the literature on the relation of individual-level health behavior constructs and screening behavior Psychooncology 2011;20:1023-33.

19 Ajzen I. The theory of planned behavior. Organ Behav Hum Decis Process 1991;50:179-211.

20 Cooke R, French DP. How well do the theory of reasoned action and theory of planned behaviour predict intentions and attendance at screening programmes? A meta-analysis. Psychol Health 2008;23:745-65.

21 Sieverding $M$, Matterne U, Ciccarello L. What role do social norms play in the context of men's cancer screening intention and behavior? application of an extended theory of planned behavior. Health Psychol 2010;29:72-81.

22 Devellis BM, Blalock SJ, Sandler RS. Predicting participation in cancer screening: the role of perceived behavioral Control1. J App Soc Psychol 1990;20:639-60.

23 Cialdini RB. Crafting normative messages to protect the environment. Curr Dir Psychol Sci 2003;12:105-9.

24 Francis J, Eccles MP, Johnston M, et al. Constructing questionnaires based on the theory of planned behaviour: a manual for health services researchers. Newcastle upon Tyne, UK: Centre for Health Services Research, University of Newcastle upon Tyne, 2004.

25 Klabunde C, Blom J, Bulliard J-L, et al. Participation rates for organized colorectal cancer screening programmes: an international comparison. J Med Screen 2015;22:119-26.

26 Robertson DJ, Lee JK, Boland CR, et al. Recommendations on fecal immunochemical testing to screen for colorectal neoplasia: a consensus statement by the US multi-society task force on colorectal cancer. Gastroenterology 2017;152:1217-37.

27 Sung JJY, Choi SYP, Chan FKL, et al. Obstacles to colorectal cancer screening in Chinese: a study based on the health belief model. Am J Gastroenterol 2008;103:974-81.

28 Wong MCS, Ching JYL, Chan VCW, et al. Informed choice vs. no choice in colorectal cancer screening tests: a prospective cohort study in real-life screening practice. Am J Gastroenterol 2014;109:1072-9.

29 Wong MCS, Ching JYL, Lam TYT, et al. Association of interactive reminders and automated messages with persistent adherence to colorectal cancer screening: a randomized clinical trial. JAMA Oncol 2017;3:1281-3.

30 Wong MC, Ching JY, Huang J, et al. Effectiveness of reminder strategies on cancer screening adherence: a randomised controlled trial. Br J Gen Pract 2018;68:e604-11. 